Pacific Journal of Mathematics

THE NON-CONJUGACY OF CERTAIN ALGEBRAS OF 


\section{THE NON-CONJUGACY OF CERTAIN ALGEBRAS OF OPERATORS}

\section{JULIEN HENNEFELD}

Let $E$ be a Banach space and $B(E)$ be the space of all bounded linear operators on $E$. It was shown by Schatten, that if $E$ is a conjugate space then $B(E)$ is isometrically isomorphic to a conjugate space. The fact that for an arbitrary Banach space, the unit ball of $B(E)$ has extreme points suggests that $B(E)$ might always be a conjugate space. In this paper it is proved that if $E$ has an unconditional basis and is not isomorphic to a conjugate space, then $B(E)$ is not isomorphic to a conjugate space. An even stronger result is proved.

Furthermore, it is shown that if $E$ has an unconditional basis or a complemented subspace with an unconditional basis, then the space of all compact linear operators on $E$ is not isomorphic to a conjugate space.

The result of Schatten is proved in [3; p. 4]. It is a theorem of Kakutani, that the identity of a Banach algebra is an extreme point of the unit ball. It follows that the invertible elements of norm one, whose inverses also have norm one, are extreme points of the unit ball. Hence, one cannot readily invoke the Krein Millman Theorem to prove non-conjugacy of $B(E)$. For $X$ and $E$ Banach spaces let $B(X, E)$ denote the space of all bounded linear operators from $X$ into $E$.

Theorem 2.1. (Bessaga-Pełczynski). A conjugate space contains no complemented subspace isomorphic to $c_{0}$.

Proof. See [1; p. 250].

THEOREM 2.2. Let $X, E$ be Banach spaces.

(1) If $E$ has an unconditional basis $\left\{e_{i}\right\}$ and $E$ is not isomorphic to a conjugate space, then $B(X, E)$ is not isomorphic to a conjugate space.

(2) If $E$ has a complemented subspace which is not isomorphic to a conjugate space and which has an unconditional basis, then $B(X, E)$ is not isomorphic to a conjugate space.

Proof. (1) Since $E$ is not isomorphic to a conjugate space, the basis $\left\{e_{i}\right\}$ is not boundedly complete [2; Cor. 12, p. 37]. Since $\left\{e_{i}\right\}$ is also unconditional, $E$ cannot be weakly sequentially complete and hence has a subspace isomorphic to $c_{0}$ by [2; Thm. 5, p. 39 and Thm. 
6, p. 71]. Then since $E$ is separable this subspace isomorphic to $c_{0}$ must be complemented [2; p. 92].

Let $Q$ be a projection from $E$ onto $M_{0}$, the subspace of $E$ isomorphic to $c_{0}$. Fix $x_{0} \in X$. Let $R$ be a projection from $X$ to $\left[x_{0}\right]$. Define $\mathscr{P}: B(X, E) \rightarrow B(X, E)$ by $\mathscr{P} T=Q T R$ for each $T \in B(X, E)$. Then $\mathscr{P}(\mathscr{P} T)=Q Q T R R=Q T R$ and hence $\mathscr{P}$ is a bounded projection. The map which sends $\mathscr{P} T$ onto $\mathscr{P} T x_{0}$ for each $T \in B(X, E)$ is a one-to-one, bounded map from the image of $\mathscr{P}$ onto $M_{0}$. Hence $B(X, E)$ has a complemented subspace isomorphic to $c_{0}$, and by Theorem $2.1 B(X, E)$ cannot be isomorphic to a conjugate space.

(2) $E$ still has a complemented subspace isomorphic to $c_{0}$.

Theorem 2.3. Let $E$ have an unconditional basis $\left\{e_{i}\right\}$. Then $\mathscr{C}(E)$, the space of compact linear operators from $E$ to $E$, is not isomorphic to a conjugate space.

Proof. The map which sends a compact operator $A$ onto the operator whose matrix with respect to $\left\{e_{i}\right\}$ consists of the diagonal of the matrix of $A$, is a bounded projection from $\mathscr{C}(E)$ onto a subspace isomorphic to $c_{0}[4 ; \mathrm{p} .493]$. Then apply Theorem 2.1 .

Corollary 2.3. Let $E$ have a complemented subspace $M$ with an unconditional basis. Then $\mathscr{C}(E)$ is not isomorphic to a conjugate space.

Proof. Let $Q: E \rightarrow M$ be a bounded projection. Define $\mathscr{P}: \mathscr{C}(E) \rightarrow$ $\mathscr{C}(E)$ by $\mathscr{P} A=Q A Q$ for each $A \in \mathscr{C}(E)$. Then $\mathscr{P}$ is a projection onto a subspace isomorphic to $\mathscr{C}(M)$. Since $\mathscr{C}(M)$ has a complemented subspace isomorphic to $c_{0}$ so does $\mathscr{C}(E)$.

REMARK. It is an open question whether a separable Banach space has a complemented subspace with an unconditional basis. It is a reasonable conjecture that for any separable Banach space $E, \mathscr{C}(E)$ is not isomorphic to a conjugate space.

The author wishes to thank the referee of a previous paper for calling his attention to the Bessaga-Pełczynski Theorem.

\section{REFERENCES}

1. C. Bessaga and A. Pelczynski, Some Remarks on Conjugate Spaces Containing Subspaces Isomorphic to the space $c_{0}$, Bull. Acad. Polon. Sci., VI, (1958), 249-250.

2. J. Marti, Introduction to the Theory of Bases, Springer-Verlag, New York, 1969.

3. R. Schatten, A Theory of Cross Spaces, Ann. Math. Studies, No. 26, Princeton University Press, Princeton, 1950. 
4. I. Singer, Bases in Banach Spaces I, Springer-Verlag, New York, 1970.

Received August 17, 1971 and in revised form February 1, 1972.

BOSTON COLLEGE 



\section{PACIFIC JOURNAL OF MATHEMATICS}

\section{EDITORS}

\section{H. SAMElson}

Stanford University

Stanford, California 94305

C. R. Новву

University of Washington

Seattle, Washington 98105
J. DugunduI

Department of Mathematics University of Southern California

Los Angeles, California 90007

RICHARD ARENS

University of California

Los Angeles, California 90024

\section{ASSOCIATE EDITORS}
E. F. BECKENBACH
B. H. NeUmanN
F. WOLF
K. YosHIDA

\section{SUPPORTING INSTITUTIONS}

UNIVERSITY OF BRITISH COLUMBIA

UNIVERSITY OF SOUTHERN CALIFORNIA

CALIFORNIA INSTITUTE OF TECHNOLOGY

STANFORD UNIVERSITY

UNIVERSITY OF CALIFORNIA

UNIVERSITY OF TOKYO

MONTANA STATE UNIVERSITY

UNIVERSITY OF UTAH

UNIVERSITY OF NEVADA

WASHINGTON STATE UNIVERSITY

NEW MEXICO STATE UNIVERSITY

OREGON STATE UNIVERSITY

UNIVERSITY OF OREGON

OSAKA UNIVERSITY

UNIVERSITY OF WASHINGTON

* *

AMERICAN MATHEMATICAL SOCIETY

NAVAL WEAPONS CENTER 


\section{Pacific Journal of Mathematics}

\section{Vol. 43, No. $1 \quad$ March, 1972}

Alexander (Smbat) Abian, The use of mitotic ordinals in cardinal

arithmetic ....................................... 1

Helen Elizabeth. Adams, Filtrations and valuations on rings ......... 7

Benno Artmann, Geometric aspects of primary lattices .............. 15

Marilyn Breen, Determining a polytope by Radon partitions ........... 27

David S. Browder, Derived algebras in $L_{1}$ of a compact group .......... 39

Aiden A. Bruen, Unimbeddable nets of small deficiency .............. 51

Michael Howard Clapp and Raymond Frank Dickman, Unicoherent

compactifications ............................... 55

Heron S. Collins and Robert A. Fontenot, Approximate identities and the strict topology ................................... 63

R. J. Gazik, Convergence in spaces of subsets................. 81

Joan Geramita, Automorphisms on cylindrical semigroups ........... 93

Kenneth R. Goodearl, Distributing tensor product over direct product ..... 107

Julien O. Hennefeld, The non-conjugacy of certain algebras of

operators ................................... 111

C. Ward Henson, The nonstandard hulls of a uniform space ........... 115

M. Jeanette Huebener, Complementation in the lattice of regular

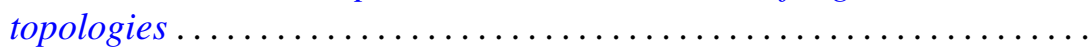

Dennis Lee Johnson, The diophantine problem $Y^{2}-X^{3}=A$ in a

polynomial ring .................................... 151

Albert Joseph Karam, Strong Lie ideals . . . . . . . . . . . . . . . . . . . . 157

Soon-Kyu Kim, On low dimensional minimal sets ............... 171

Thomas Latimer Kriete, III and Marvin Rosenblum, A Phragmén-Lindelöf

theorem with applications to $M(u, v)$ functions ..... . .

William A. Lampe, Notes on related structures of a universal algebra . . . . 189

Theodore Windle Palmer, The reducing ideal is a radical .

207

Kulumani M. Rangaswamy and N. Vanaja, Quasi projectives in abelian and module categories ................................ 221

Ghulam M. Shah, On the univalence of some analytic functions ......... 239

Joseph Earl Valentine and Stanley G. Wayment, Criteria for Banach

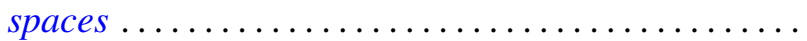

Jerry Eugene Vaughan, Linearly stratifiable spaces ............... 253

Zbigniew Zielezny, On spaces of distributions strongly regular with respect to partial differential operators ..................... 